\title{
BREATHLESSNESS AND PALLIATIVE OXYGEN THERAPY IN ADVANCED CHRONIC OBSTRUCTIVE
}

\section{PULMONARY DISEASE}

Short title: Palliative oxygen therapy in COPD

\section{Authors \& Affiliations}

Corresponding Author: Dr Natasha Smallwood

Dr Natasha Smallwood MBBS, SpecCertPallCare, MEpid, MRCP, FRACP

Respiratory Physician. Department of Respiratory and Sleep Medicine, The Royal Melbourne Hospital, Royal Parade, Parkville, Victoria 3050, Australia.

Tel: 039342 7708. Fax: 039342 8493. Natasha.smallwood@mh.org.au

Dr Nicole Gaffney MBBS MPHTM FRACP

Respiratory Physician. Department of Respiratory Medicine, Frankston Hospital, 2 Hastings Road, Frankston, Victoria 3199. nicgaffney@gmail.com

Mrs Alexandra Gorelik BA(Stats), MSc

Senior Statistician. Melbourne EpiCentre, The Royal Melbourne Hospital, Parkville, Victoria 3050. alexandra.gorelik@mh.org.au

A/Prof Louis Irving MBBS, FRACP

This is the author manuscript accepted for publication and has undergone full peer review but has not been through the copyediting, typesetting, pagination and proofreading process, which may lead to differences between this version and the Version of Record. Please cite this article as doi: 10.1111/imj.13748

This article is protected by copyright. All rights reserved. 
Respiratory Physician and Director Department of Respiratory and Sleep Medicine, The Royal Melbourne Hospital, Parkville, Victoria 3050, Australia. Louis.irving@mh.org.au

A/Prof Brian Le MBBS(Hons), MPH, FRACP, FAChPM

Palliative Medicine Specialist and Director Department of Palliative Care, The Royal Melbourne Hospital, Parkville, Victoria 3050, Australia. Brian.le@mh.org.au

Prof Jennifer Philip MBBS, GrDipPallMed, MMed, FAChPM, PhD

Palliative Medicine Specialist and Deputy Director Centre for Palliative Care, St Vincent's Hospital, Victoria Parade, Fitzroy, Victoria 3065, Australia. Jennifer.philip@svha.org.au

Word Count - 500

References -8

Keywords

COPD, oxygen, dyspnea, survey, palliative, knowledge

\section{Acronyms}

COPD - Chronic obstructive pulmonary disease

POT - Palliative oxygen therapy

This article is protected by copyright. All rights reserved. 


\section{To the editor}

We recently reported in the IMJ that junior doctors report high awareness, confidence, willingness and experience prescribing opioids to COPD patients with refractory breathlessness [1]. However, opioids are only the final step in a comprehensive management plan, which should first include nonpharmacological strategies such as smoking cessation, self-management education, physical activity, pulmonary rehabilitation, breathing exercises and the use of a handheld fan [2-4]. In this letter, we describe junior doctors' knowledge and views regarding these strategies and palliative oxygen therapy.

From the 223 full survey responses received, there was limited recommendation of nonpharmacological strategies for refractory breathlessness, with the three most commonly recommended being pulmonary rehabilitation (30.0\%), using a handheld fan (14.8\%), and anxiety management and relaxation techniques (13.0\%). Similarly, very few trainees recommended multidisciplinary input from nursing or allied health professionals such as community nurses (3.6\%) or physiotherapists $(8.1 \%)$, and only $6(2.7 \%)$ recommended patient and carer education to reduce breathlessness

Approximately half of the respondents $(116,52.0 \%)$ believed that palliative oxygen therapy (i.e. oxygen therapy used at rest in patients who do not qualify for long-term oxygen therapy) relieved refractory breathlessness in patients who do not have severe hypoxaemia, while 45 (20.2\%) were unsure. Twelve trainees indicated that oxygen might improve dyspnoea by reducing anxiety or by having a placebo effect. The belief that oxygen relieves refractory breathlessness was not associated with any trainee demographic characteristics.

These findings may be explained by the trainees' early career stage and the fact that they predominantly work as part of a consultant-led team managing inpatients. In that setting, there is

This article is protected by copyright. All rights reserved. 
ready access to an expert, multidisciplinary team including physiotherapists and occupational therapists, who can educate patients regarding self-management and non-pharmacological breathlessness strategies. Thus, the medical team may be more focussed on diagnosis and prescribing appropriate medications for refractory breathlessness. Additionally, trainees may assume that similar structures of multidisciplinary care are in place and accessible in the community.

Recent studies suggest that palliative oxygen therapy (POT) is burdensome and does not improve refractory breathlessness, quality of life or survival $[5,6]$. However, in a small minority of patients POT may relieve breathlessness, therefore oxygen prescription must be individualised [7]. Physicians are divided as to the benefits of POT, with $58 \%$ of respiratory physicians and palliative care specialists in Australia and New Zealand surveyed in 2005, believing that palliative oxygen therapy is beneficial [8]. Given the similar results in our recent study, disappointingly the latest evidence has not translated into clinical knowledge.

Surveys are challenging as respondents have to choose definitive answers to clinical questions, which in reality require cautious evaluation for individual patients. Similarly, participants may make implicit assumptions regarding clinical management, when responding to case vignette scenarios. However, our findings suggest that Australian junior doctors' focus on pharmacological treatments [1] and oxygen for refractory breathlessness, and have less awareness of the evidence-based, multidisciplinary, non-pharmacological interventions, which come first in clinical practice. Further education regarding refractory breathlessness management and particularly using a comprehensive, stepwise approach is required to translate evidence into practice.

This article is protected by copyright. All rights reserved. 


\section{Declaration of interests}

Dr Natasha Smallwood received research funding to support this work as part of her PhD from Palliative Care Research Network (Australia) and the Australian Commonwealth Government through the Australian Government Research Training Program. The other authors report no conflicts of interest.

This article is protected by copyright. All rights reserved. 


\section{References}

1. Smallwood, N., et al., Junior doctors' attitudes to opioids for refractory breathlessness in patients with advanced chronic obstructive pulmonary disease. Intern Med J, 2017. 47(9): p. 1050-1056.

2. GOLD, Global initiative for chronic obstructive lung disease (GOLD). Global strategy for the diagnosis, management and prevention of COPD (2017 report). Available from: www.goldcopd.org. Accessed January 2017. 2017.

3. Marciniuk, D.D., et al., Managing dyspnea in patients with advanced chronic obstructive pulmonary disease: a Canadian Thoracic Society clinical practice guideline. Can Respir J, 2011. 18(2): p. 69-78.

4. Yang, I., et al., The COPD-X Plan: Australian and New Zealand Guidelines for the management of Chronic Obstructive Pulmonary Disease 2016. Version 2.47, Oct 2016. 2016, www.copdx.org.au.

5. Abernethy, A.P., et al., Effect of palliative oxygen versus room air in relief of breathlessness in patients with refractory dyspnoea: a double-blind, randomised controlled trial. Lancet, 2010. 376(9743): p. 784-93.

6. Long-Term Oxygen Treatment Trial Research Group, A Randomized Trial of Long-Term Oxygen for COPD with Moderate Desaturation. N Engl J Med, 2016. 375(17): p. 1617-1627.

7. Ekstrom, M., et al., Oxygen for breathlessness in patients with chronic obstructive pulmonary disease who do not qualify for home oxygen therapy. Cochrane Database Syst Rev, 2016. 11: p. CD006429.

8. Abernethy, A.P., et al., Prescribing palliative oxygen: a clinician survey of expected benefit and patterns of use. Palliat Med, 2005. 19(2): p. 168-70.

This article is protected by copyright. All rights reserved. 


\section{University Library}

\section{- M M N E R VA A gateway to Melbourne's research publications}

Minerva Access is the Institutional Repository of The University of Melbourne

Author/s:

Smallwood, N;Gaffney, N;Gorelik, A;Irving, L;Le, B;Philip, J

Title:

Breathlessness and palliative oxygen therapy in advanced chronic obstructive pulmonary disease

Date:

2018-04-01

Citation:

Smallwood, N., Gaffney, N., Gorelik, A., Irving, L., Le, B. \& Philip, J. (2018). Breathlessness and palliative oxygen therapy in advanced chronic obstructive pulmonary disease.

INTERNAL MEDICINE JOURNAL, 48 (4), pp.483-+. https://doi.org/10.1111/imj.13748.

Persistent Link:

http://hdl.handle.net/11343/283852 